Abstracta Iranica Abstracta Iranica

Revue bibliographique pour le domaine irano-aryen

Volume 27 | 2006

Comptes rendus des publications de 2004

\title{
Mazorhoi shumoli Tojikiston. Douchanbe, Nashriioti Devashtich, 2004, 200 p., ill. [Les sanctuaires du nord du Tadjikistan]
}

\section{Stéphane A. Dudoignon}

\section{(2) OpenEdition}

1 Journals

Édition électronique

URL : http://journals.openedition.org/abstractairanica/6198

DOI : 10.4000/abstractairanica.6198

ISSN : 1961-960X

Éditeur :

CNRS (UMR 7528 Mondes iraniens et indiens), Éditions de l'IFRI

Édition imprimée

Date de publication : 15 mai 2006

ISSN : 0240-8910

Référence électronique

Stéphane A. Dudoignon, «Mazorhoi shumoli Tojikiston. Douchanbe, Nashriioti Devashtich, 2004, 200 p., ill. [Les sanctuaires du nord du Tadjikistan] », Abstracta Iranica [En ligne], Volume 27 | 2006, document 261, mis en ligne le 02 janvier 2007, consulté le 25 septembre 2020. URL : http://

journals.openedition.org/abstractairanica/6198; DOI : https://doi.org/10.4000/abstractairanica.6198

Ce document a été généré automatiquement le 25 septembre 2020

Tous droits réservés 


\title{
Mazorhoi shumoli Tojikiston. Douchanbe, Nashriioti Devashtich, 2004, 200 p., ill. [Les sanctuaires du nord du Tadjikistan]
}

\author{
Stéphane A. Dudoignon
}

Auteur d'un précédent ouvrage remarqué sur les sanctuaires (mazārs) de la ville et de la région de Khoudjand (Chahordah mazor [Quatorze sanctuaires] Khoudjand, 2003), H.K. présente une suite de notices sur les sanctuaires islamiques et islamisés de la basse vallée de Zerafchan (Pendjikent, Falghar) et du Ferghana occidental (Khoudjand, Istrawshan, Isfara), suivie de considérations sur la typologie des mazārs, sur les rituels associés à leur visite, et sur l'histoire de leur mode de financement à l'époque moderne et contemporaine. La version russe publiée un an plus tard chez le même éditeur (Istoriia mazarov severnogo Tadzhikistana [Histoire des sanctuaires du Tadjikistan septentrional], 2005) offre une version sensiblement différente de l'original tadjik, plus aboutie et davantage illustrée. Il faut cependant regretter que, d'une manière générale pour ses ouvrages sur les sanctuaires du Tadjikistan, l'A. tende à limiter sa documentation aux travaux académiques les plus récents des savants de Douchanbe, sans s'intéresser beaucoup ni à une abondante littérature ethnographique russe et soviétique, ni aux sources primaires en persan conservées à Douchanbe sous forme de manuscrits, ou éditées en caractères arabes ou cyrilliques depuis la fin des années 1980. Il est plus dommage encore que la riche oralité attachée aux sanctuaires étudiés n'ait été que très peu sollicitée, alors même qu'elle recèle des éléments souvent déterminants non seulement sur la mythologie, mais aussi sur l'histoire de ces lieux saints. A déplorer enfin: l'absence totale de croquis des plans et élévations des monuments étudiés, pourtant utiles dans la perspective d'études typologiques. Autant de lacunes qui témoignent d'une certaine précipitation et de la recherche de sensationnel qui caractérisent les travaux d'érudition dans les pays d'Asie Centrale anciennement soviétiques, surtout lorsque ces derniers bénéficient de financements étrangers étalés sur des durées le plus souvent très brèves (le présent ouvrage ayant été 
soutenu par le bureau de Douchanbe de l'Agence suisse pour la Coopération et le Développement).

INDEX

Thèmes : 7. Islam

AUTEURS

STÉPHANE A. DUDOIGNON

CNRS - Paris 